\title{
Iraqi architecture in mogul period
}

\author{
Shatha Hasan $^{1, *}$ and Yasameen Rasheed ${ }^{1}$ \\ ${ }^{1}$ Department of Architecture - College of Engineering, University of Baghdad, Baghdad, Iraq
}

\begin{abstract}
Iraqi architecture have many periods passed through it until now, each on from these periods have it is architectural style, also through time these styles interacted among us, to creating kind of space forming, space relationships, and architectural elements (detailed treatments), the research problem being from the multi interacted architectural styles causing some of confused of general characteristic to every style, that we could distinguish by it. Research tries to study architecture style through Mogul Conquest to Baghdad. Aim of research follow main characteristic for this architectural style in the Mogul periods on the level of form, elements, and treatments. Research depending on descriptive and analytical all buildings belong to this period, so from analyzing there style by, general form for building, architectural elements, and it architectural treatment, therefore; repeating this procedures to every building we get some similarities, from these similarities we can making conclusion about pure characteristic of the style of these period. Other side, we also discover some Dissimilar in the building periods, these will lead research to make what interacting among styles in this period, after all that we can drew clearly main characteristic of Architectural Style for Mogul Conquest in Baghdad
\end{abstract}

\section{Introduction}

There many periods through any civilization, every period must be have comment characteristics that we can recognize from it, the most important and significant characteristic that be permanent and durable with time, like physical structure, when we wont to research about any records to any periods, firstly we look on architecture of this period, so we can imagination period facts when we intersect documented information with building architecture of this period.

In this research we look for very important period in history of Baghdad, Mogul Period, many sources referring to this period as dark period, may be the hard circumstance clear some facts in this way, but there are other way referring to ability of society to live and resistance ant conditions, from that we have many evidence in many Iraqi Cities showing create building architecture in this period.

Research build it is methodology on clarify the building belongs to Mogul Period, and then try to comparing among them, to reach define common architectural characteristics that be occurring the main character of this period.

\section{Selecting building}

Research put criteria for selecting building depends on:

1. History of building must be clear.

2. Structure of building was obvious and without modification.

So, the buildings will be analyzed in levels as:

1. The general form

2. Architectural elements

3. Treatment

In this way, we can identify the characteristics of the era style, Table (1), shows selected buildings to apply comparative analysis among them.

Table 1: Buildings in Case Study

\begin{tabular}{|l|l|l|}
\hline Building name & Dates & Using \\
\hline Omer Al Shrawrdy Shrine & 1334 & Shrine \\
\hline Minaret Alaqoly Mosque & 1327 & Mosque \\
\hline $\begin{array}{l}\text { Minaret Alkhukafa'a } \\
\text { Mosque }\end{array}$ & 1271 & Mosque \\
\hline Merjan School & 1357 & School \\
\hline Merjan Khan & 1358 & Motel \\
\hline
\end{tabular}

* Corresponding author: shatha arch2010@yahoo.com 


\section{Buildings descriptive}

Research try in this paragraph to get general descriptive to all building we'll discuss it:

\subsection{Omer Al Shrawrdy shrine}

Shrine location is in historical city center of Baghdad city, Rusafa side, building nearly 1334; the shape is simple, rectangular, with conic tomb. The tomb based on square base, length of it about $(4.9 \mathrm{~m})$, creating mosque shape beside the rectangular.

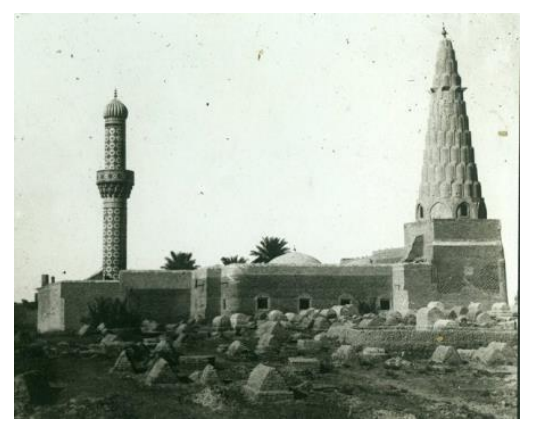

Figure 1: Omer Al Shrawrdy Shrine

\subsubsection{Architectural elements}

The building of entrance is having the same shape without modification, with writing ornament by brick. The tomb dome consist of (10) layers of Muqarnas, direction of it to inside. There are four opens in the dome, shape of them as vault, using for ventilation and lighting. Mosuqe minaret is having three lyres of Muqarnas, supporting Muezzin balcony, this minaret was built in the Ottomans era.

\subsection{Manarate Alaqoly mosque}

The Aqoly mosque located in the middle of Rasheed Street, nearing Hayderkhana mosque, built at 1327, then renovated at 1802 , also after 50years renovated too. (Editors, 2013, p.250)

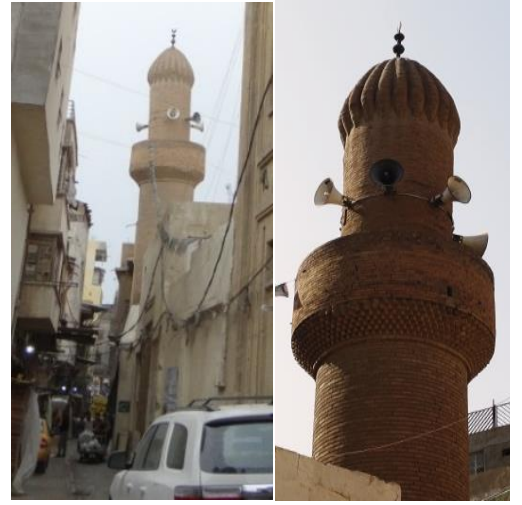

Figure 2: Minaret Alaqoly Mosque

Source: field survey

\subsubsection{Architectural elements}

Mosque minaret is having wide body, based on rectangular shape, with six layers of Muqarnas, minaret height was nine meter, and proportion of it is height to width is (1:3.6). (Sid Mahmoud, 1346, p.47). The entrance of minaret is simple without any ornament, and the basic building unit is brick, with white color due to coated by gypsum. (Editors, 2013, p.250).

\subsection{Minaret Al Khukafa'a mosque}

The minaret is having cylindrical shape, with huge base, and having two balconies. It was built at 1179 , and then after it is damaged, renovated at 1271, in the time of Alaa Al Dein Aljouany in the Mogul era. (Sid Mahmoud, 1346, p.38)

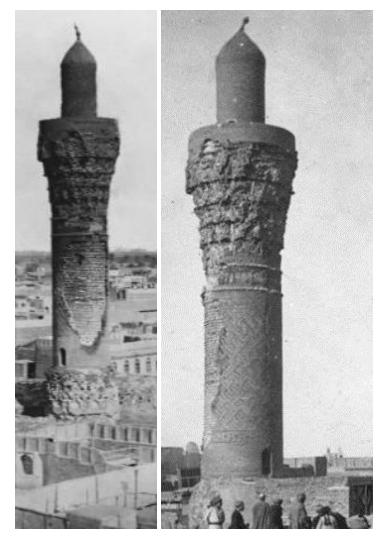

Figure 3: Minaret Alkhukafa'a Mosque

Source: field survey

\subsubsection{Architectural elements}

The original height of minaret was 35 meter, with (8) meter diameter, the proportion of height to width is 
(1:4). All faces of minaret body decorated with patterns of lettering as ornament by bricks, and we can recognize Koufi style in these letters. (Refa'at, 2014, p.82), the Muezzin balcony based on Muqarnas without decoration; just consist of composed four lyres of Muqarnas. (Tariq, 1982, p.95) main basic material was brick, (Yousif, 1982, p.397).

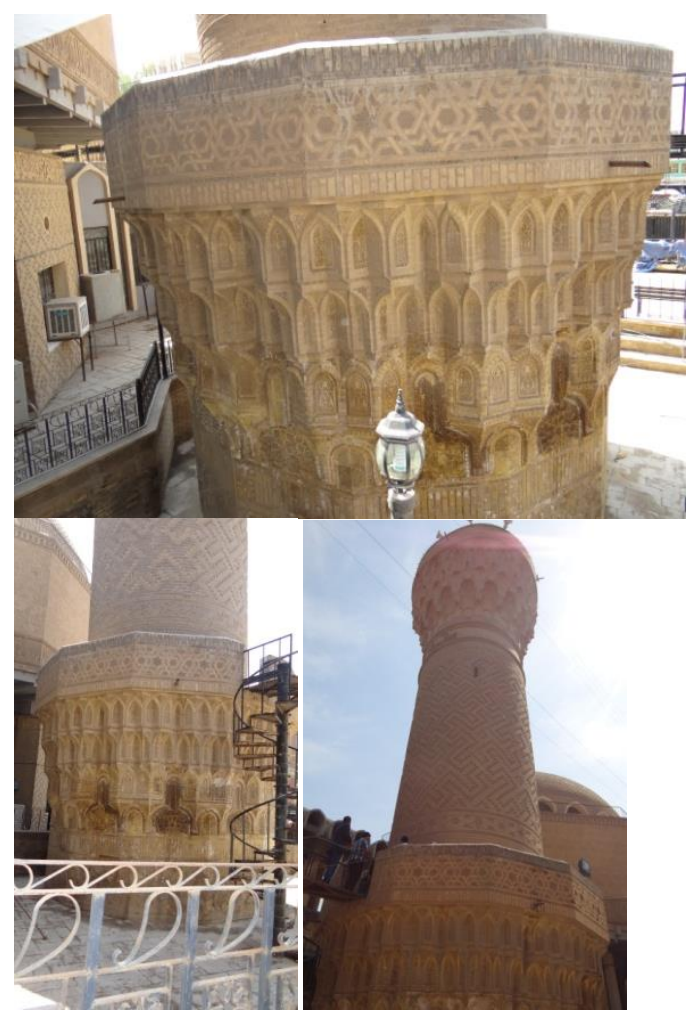

Figure 4: Muezzin balcony in the Minaret Alkhukafa'a

Source: field survey

\subsection{Merjan School}

It is called by Merjan according to persons who built it, Ammen Al Deen Merjan, at 1367; it is located in the last part of Rasheed Street, nearing Tigress River. (Sid Mahmoud, 1346, p.65)

\subsubsection{Architectural elements}

The building is consisting of two floors, it is height about ten meter, with (40) meter in width, and (18) meter long, it is proportion of width to height it was (1:4). Building was divided into two parts, school and mosque, having central court, and three big domes. (Yousif, 1982, p.520).

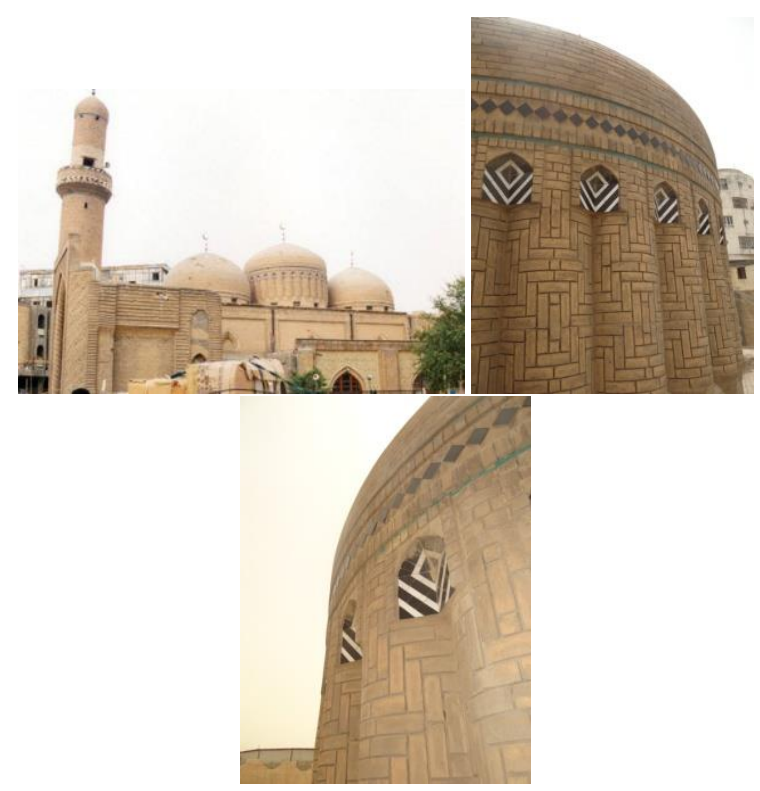

Figure 5: Merjan School and Mosque

Source: field survey

The school have huge gate in it is entrance, decorated by cylindrical ornament column, it is shape tapered vault. The main dome above shrine is based on long cylinder of bricks, decorated by geometric pattern from brick also. (Khalid, 2013, p.142)

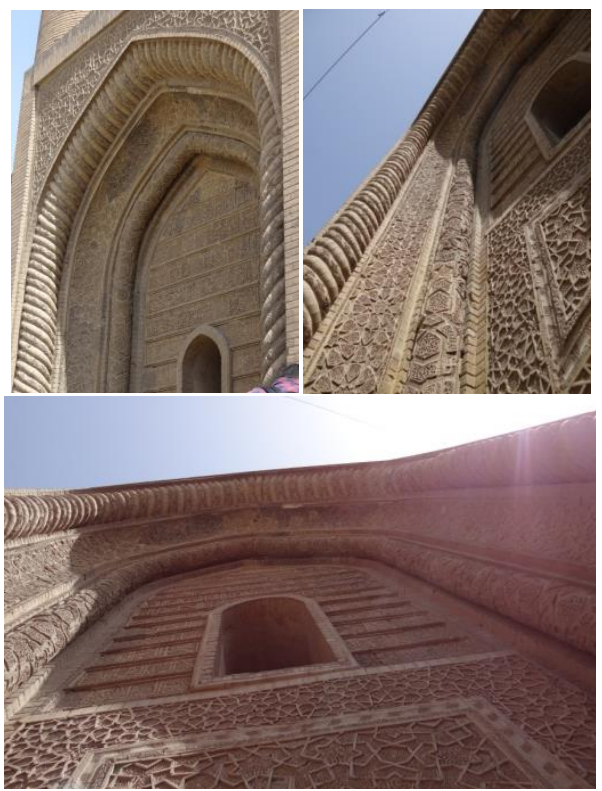

Figure 6: Gate of Merjan Mosque

Source: field survey

The relationship between mosque and school are through three big gates, with tapered vaults, (Khalid, 2013, p.180), the middle one is the bigger from the 
others, and decorated by geometric and lettering ornament patterns. (Yousif, 1982, p.522).

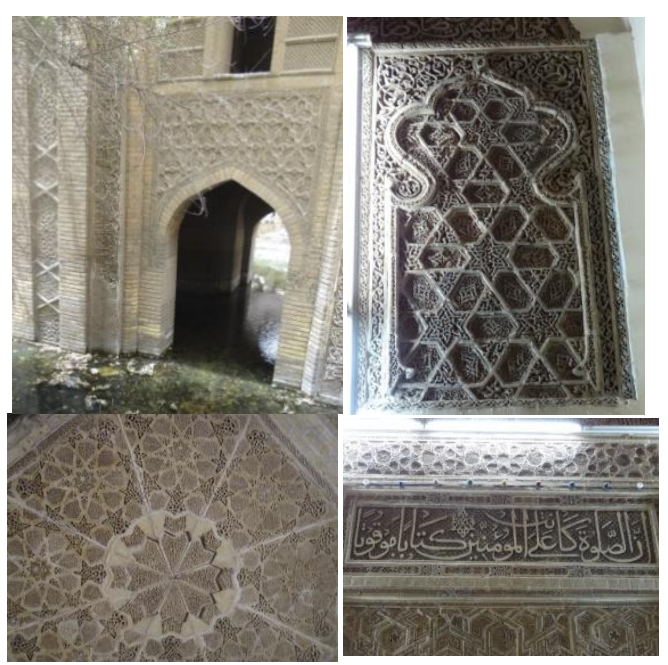

Figure 7: Decoration inside Merjan Mosque

Source: field survey

\subsection{Merjan Khan}

The function of Khan is commercial, like motel, it used by traveler especially merchants among cities. So Merjan Khan related to Merjan School, occurring one of funded sources to the school, it is also named Ortema Khan. (Sid Mahmoud, 1346, p.66)

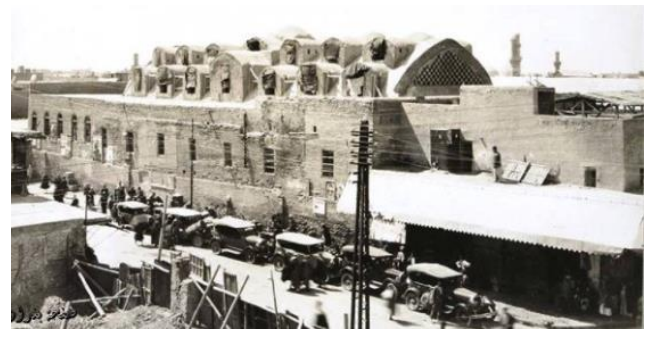

Figure 8: Merjan Khan

\subsubsection{Architectural elements}

Khan shape is rectangular, (11.4) meter width, with (30.25) meter long, the proportion of width to long was (1:2.7). (Ali, 2007).

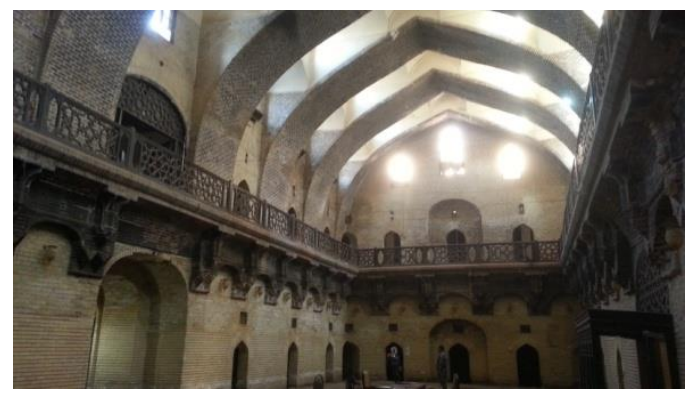

Figure 9: Roofing of Merjan Khan

Source: field survey

The Khan consist of two floors, the first one, having continues indoor balcony, viewed on ground floor, on it is court. This balcony based on supported wall, length of each one about (1) meter.

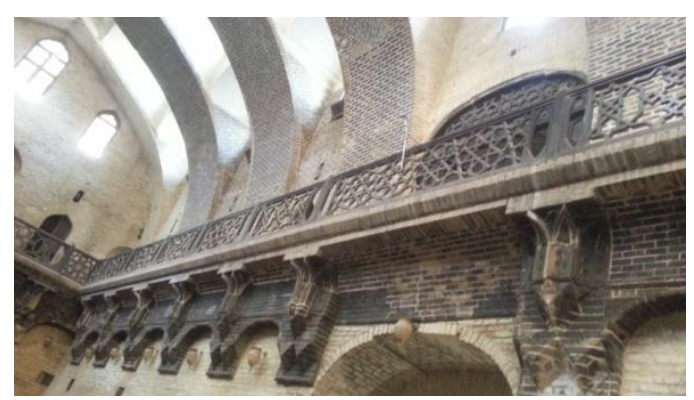

Figure 10: Balcony in Merjan Khan 
Source: field survey

The court is roofing by (8) intersected vaults, width of each one is (2.5) meter, height point about (14) meter.

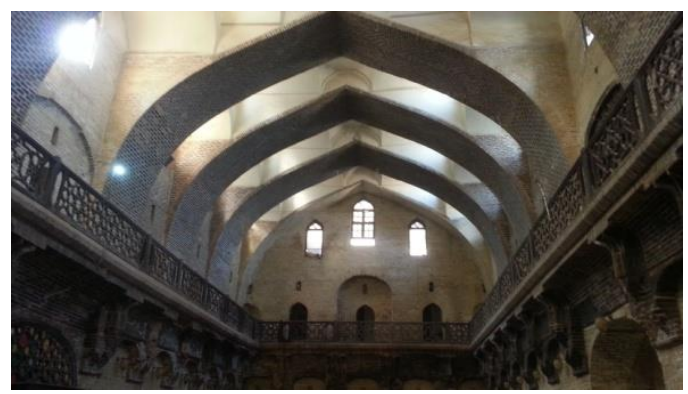

Figure 11: Vaults in Merjan Khan

Source: field survey

Windows opens in the ground floor have small horizontal rectangular, and thus in the first floor it was bigger and with vaults. (Khalid, 2013, p.121)

They are no more decoration in the khan, except the main gate and it is entrance, was decorated by geometric pattern, consist of octagonal stars, main building material was brick only with wood. (Ahmed, 2013, p.20)

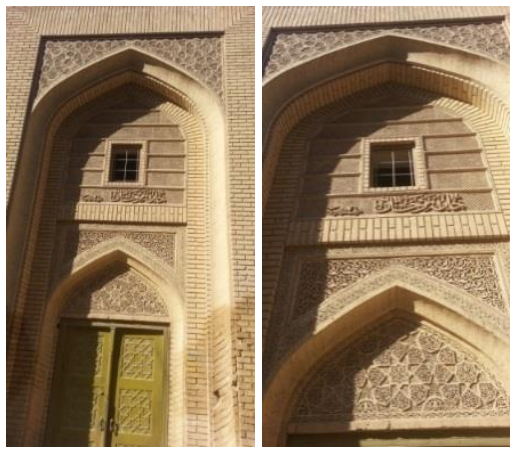

Figure 12: Gate of Merjan Khan

Source: field survey

\section{Analysis of the general form}

1. The rectangular shape is prevailing on the building's general form with the ratio of length to width in average of (1:3)

2. The presence of the central courtyard or yard (Sahan) in the roofed buildings - which the space or different rooms open toward it by a structural ratio of (1:2.5).
3. The overall height of buildings is two stories with average of $(10 \mathrm{~m})$.

4. The entrance is prominent with a height of two stories and may be higher than the building itself, ornamented, with a structural ratio of (1: 1.5).

5. The external facades are solid and if there are openings, they are either at the level of the ground floor, small or elevated horizontal.

6. Buildings are free of adornments and ornaments, except in the entrances and domes.

7. The horizontal lengthiness of the building ration is of $(1: 5)$.

\subsection{Architectural elements}

\subsubsection{The entrance}

1. The entrances with a height of two stories with a ration of $(1: 1.5)$.

2. Higher than the main building.

3. The entrance mainly consists of a rectangular external frame.

4. The presence of decorative rectangle above the threshold of the door.

5. The decorations differ:

- Some were limited to radial decoration, similar to floral compositions, while others were limited to geometric motifs.

- The presence of twisted columns in Merjan School only after it was first found in decorations of the Abbasid palace columns and has been absent until it reappeared here.

\subsubsection{The dome}

1. Seljuk style domes continue to present as a continuation of the Abbasid era.

2. The Dome (onion shaped) with a neck.

3. The emergence of triangles corner for the first time in the domes of this period.

4. The domes were not devoid of some simple inscriptions and decorations at times.

5. The presence of small openings for functional purposes in the domes

\subsubsection{Minaret}

1. The minarets height differed but the structural ratio remained close to $1: 3.5$.

2. The minarets unified by a candle onion shaped striated dome despite the difference in final treatment.

3. The decorations and ornaments appeared only on the minaret of the Khulafaa Mosque in crossing stripes.

4. The minarets are based on the adjacent building or on an independent base. 
5. The minarets balcony is based on six layers of muqarnas rows in the minarets of Merjani School and Aqouliya mosque.

6. The great difference Khulafaa Mosque minaret from the rest of the minarets, probably due to the Abbasid origin.

See Minaret of al - Sahrawardi tomb, minaret of the Aqouliya mosque, minaret of the mosque of the Khulafaa, minaret of Merjan mosque.

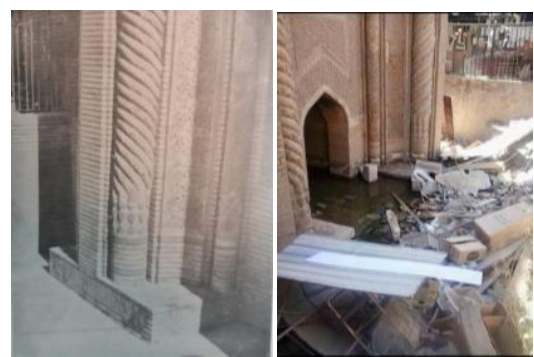

Figure 13: Cylindrical Decoration in Gate of Merjan Mosque

Source: field survey

\subsubsection{Arches}

1. The dominant type of arces is Tudor arches, although continuous appearance of pointed arch.

1. The different ratios were used in arches construction and ranged from (1: 1.5-1:2).

2. The arches are decorated with geometric motifs, if any. See Suhrawardi, Khan Merjan , Merjan School

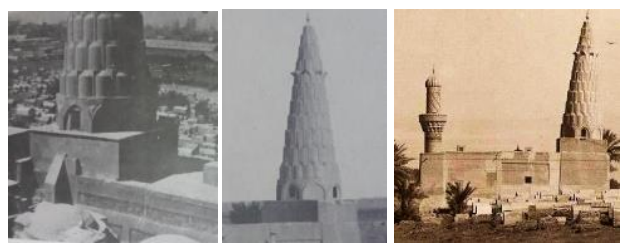

Figure 14: Comparative Dome with Omer Al Shrawrdy Shrine Dome

\subsubsection{The vault}

1. The vault used for Khan roof, a phenomenon appeared for first time.

2. Cross-sectional vaults with half-circular section were used.

\subsubsection{The iwan}

1. The obvious formalistic similarity with the Abbasid era's Iwan, and its length to the width ratio (1:2).

2. Detailing treatments differed from the previous era by the introduction of inscriptions and facing with marble.
3. Iwan remains an important element in the building formation and di the height of the building has not been increased or become salient.

\subsubsection{The gallery}

1. The continuation of gallery element appearance in the case of buildings and mosques.

2. The used arches are Tudor arches.

\subsubsection{The courtyard}

1- The courtyard did not have a specific shape. The Merjan school's courtyard is similar to the Abbasid palace one with its semi-square shape before the adding of the mosque's gallery, while the Khan has a rectangular courtyard surrounded by four sides and a roof.

2- The structural ratio of courtyards is proximate at $(1: 2.5)$.

3- $\quad$ The floor is paved with the square bricks.

\subsubsection{The openings}

1- The rectangular openings are purely for the functional purposes in the minarets and are ornaments free, and they are a continuation of openings of Abbasids era.

1- Ornaments free Tudor arches, a type that appeared in more than one example: an opening with a Tudor arch enclosed by a rectangular frame containing the inscriptions and it is similar to the buildings of the Abbasid era in terms of the decorated rectangular shape.

2- $\quad$ The structural ratio for openings of this era is $(1: 1.70)$

\section{4-2 Analysis of architectural treatments}

\subsubsection{Ornaments and inscription}

1. Plant decoration is the dominant decorative element, especially in floral form.

2. The geometric ornaments appearance, but only a few and at Merjan School only.

3. The Twisted frame appears once again at Merjan School only. 


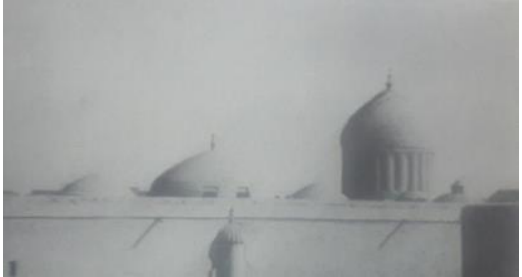

Figure 15: Demolished part from Merjan School

\section{Muqarnas}

1- The Muqarnas are different forms in this era in terms of form and number, they are serrated.

2- The decorative filling of the Muqarnas have geometric shapes, which distinguished it from the Abbasid era buildings.

\section{Buildings inscription treatments}

1. The Thulth calligraphy used in the inscription of Mughal era.

\section{Building materials}

1. The basic material in construction during this era was the baked brick

2. Inlaying of Kashani (glazed brick) in some places for aesthetic purposes.

3. Using the timber in the windows.

\subsubsection{Buildings color}

1. The predominant color for the buildings of this era yellow of the baked brick.

2. The buildings are not free from some color treatments such as in Muqarnas of Khan Merjan or color inlying of Merjan School.

\section{Discussion and conclusions of the Mogul era buildings}

\subsection{The building form}

\subsubsection{The shape}

1- The rectangular shape prevailed on the general form of the building with a ratio of $(1: 3)$.

2- The presence of open or roofed courtyard. The overall height of the buildings is $(10 \mathrm{~m})$.

3- External facades are solid and, if there are openings, they are either small located at the level of the ground floor or elevated horizontal.

4- The buildings have no decoration except in the entrances and domes.

\subsection{Architectural elements}

\subsubsection{The entrance}

1. The entrances to the height of two stories with a structural ratio of $(1: 1.5)$.

2. They exceed the height of the original building.

3. The entrance consists mainly of a decorated rectangular external frame with geometric or floral motifs.

\subsubsection{The dome}

1- The onion shaped domes emerged and belong to the Abbasid era.

1. The emergence of triangles corners for the first time in domes of this era.

2. The domes are free of inscriptions and decorations that adorn them.

\subsection{Detailed treatments}

\subsubsection{Ornaments}

1- Plant ornaments are the dominant decorative element, particularly in floral form.

2- The little appearance of geometric decorations.

3- The twisted appears again at Merjan School only, after it was used only in the Abbasid palace, but in Merjan School the reefs is older than the decorations of the Abbasid palace, because the detailed treatment of the Abbasid palace did not reach to the present.

\subsection{Architectural elements}

\subsubsection{The minaret}

1. The structural ratio $(1: 3.5)$.

2. The minarets unified with an onion shaped dome.

3. The decorations and inscriptions only appeared on the minaret of the Khulafaa Mosque in the form of cross ribbons affected by the Abbasid head.

4. The minarets are based on the ceiling of the prayer hall.

5. The minaret balconies are based on muqarnas layers of six rows in the minarets of Merjan School and Aqouliya Mosque. 


\subsubsection{Arches}

a. The predominant type of arches is the Tudor arch, despite the continuity of the pointed arch.

1. Different ratios were used in arches construction and ranged between (1: 1.5-1:2).

2. The Arches were decorated with geometrical ornaments, if any decorations.

\subsection{Detailed treatments}

\section{5-5-1 Muqarnas}

1- The forms of Muqarnas differ in this era in terms of form and number.

2- The muqarnas have no decorative fillings.

\subsubsection{Inscription treatments}

1- The inscription in Thulth calligraphy is the characteristic of the era.

2- Used in the Koran and historical inscriptions

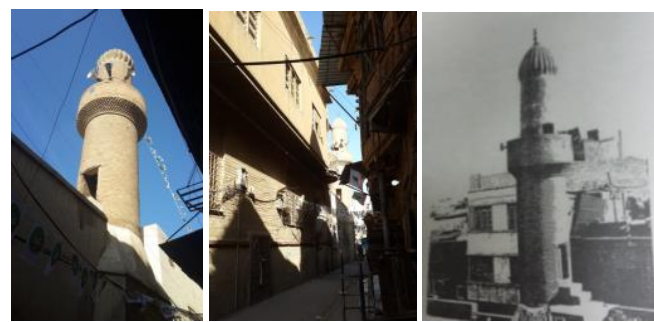

Figure 17: Alaqoly Mosque Minaret

Source: field survey

\subsection{Architectural elements}

\subsubsection{The courtyard}

1- The structural ratio of both courtyards is similar at $(1: 2.25)$.

2- The floor paved with baked brick square tiles.

\section{5-6-2 The hallway}

1- The hallway is with flat roofing.

2- The hallway appeared on the upper floor.

\section{5-6-3 The iwan}

1- The element of Iwan was emphasized and its length to width ratio is $(1: 2)$.

2- Rises for two stories.

3- The Iwan facade was decorated.

\section{5-6-4 The openings}

1- The rectangular openings were purely for functional purposes in minarets and free of ornaments

2- The predominant openings were the Tudor arches ones.

3- Slotted arch openings have also emerged.

\section{5-7 Detailing treatments}

\section{5-7-1 Building materials}

The baked brick was used in buildings of this era.

\section{5-7-2 Color treatments}

The yellow color of baked brick is the predominant color on buildings of this era.

\section{Final conclusions}

After the analysis of the buildings which were built up under the Mughal occupation and the submitting buildings still remains to be inferred, the research reached to several important points that may not have been aware of because the historical overlaps abundance, and the various factors rotation on city of Baghdad and its buildings...

Research, over selected period of time, investigated the possibility of diagnosing its style.

The research comes out with several important points that can be summarized as follows:

1- The buildings of the Mughal era (Mughal style) its architecture witnessed proximities to Abbasid era architecture:

2- The horizontal orientation is the prevailing trend in the buildings, despite the characterized immensity.

3- The attention in entrances, and they were very similar to the entrances of Abbasid era, with emergence of new types of decorations.

4- The central courtyard continued to be the mainstay of the buildings and the roofed central courtyard appeared and was a new phenomenon.

5- The dome of this era was characterized by being flat with the use of Abbasid domes with long neck with it.

6- $\quad$ The arches used during that period were the pointed arches. 
7- No clear style was discovered for this era minarets, which were different, but generally have a thick body compared to the height.

8- The use of muqarnas in the minaret reaches to six layers.

9- The Khulafaa Mosque minaret (Minaret of Suq-Ilgazil) is a double-style minaret. It was built in a transition era between the Abbasid and Mughalian eras. It has the base of Abbasid era, so it is a hybrid style minaret.

The emergence of corner curves for the first time in the buildings of this era to roof the domes.

\section{References}

1. Al Alousy, Sid Mahmoud Shukry, Mousuqe History in baghdad and it is effect, Dar Alsalam Press, (1346 H).

2. Al Janabi, Tariq, (Studies in mediaeval Iraqi architecture, Dar AlHuriaa press, (1982).

3. Al Saffar, Refa'at Marhoon, (Older Baghdadi neighborhood in the memory), Wisdom Dar, London, (2014).

4. Hamoudy, Khalid Khalil, Mierjan school in Baghdad, historical, architecture, and art study, Publisher Scientific Books Dar, Ministry of Culture, $1^{\text {st }}$ edition, (2013).

5. Researchers and Historian, 2013, Mustensiryah School History in Baghdad, Publisher Scientific Books Dar, Ministry of Culture.

6. Shiref, Yousif, Art history of Iraqi architecture, in many ages, Dar Al Rasheed for Publshing, Ministry of Culture, (1982).

7. Susa, Ahmed, Jouad, Mustafa, Detail guide for Baghdad map in Baghdad plans, new and old, Mesopotamia press, $2^{\text {nd }}$ edition, (2013).

8. Thouiny, Ali, Civilized conversation, Researches and Studies in History, Language, and Heritage, no.1940, (2007). 